\title{
Influence of phototherapy on sensorimotor excitability of healthy muscle
}

\author{
Jolanta Zwolińska', Aneta Weres ${ }^{1}$, Andrzej Kwolek ${ }^{1}$ \\ ${ }^{1}$ Department Institute of Physiotherapy, Medical University of Rzeszow, Poland
}

Zwolińska J, Weres A, Kwolek A. Influence of phototherapy on sensorimotor excitability of healthy muscle. J Pre-Clin Clin Res. 2016; 10(1): 23-27. doi: $10.5604 / 18982395.1208184$

\begin{abstract}
The aim of this study is to assess the influence of laser irradiation and incoherent infrared radiation on sensorimotor excitability and muscle pain after a workout. The research was carried out on 40 healthy volunteers who were randomly divided into four groups. A single phototherapy treatment, preceded by the triceps calf muscle workout, was applied in all the groups. Group 1: low-level laser therapy (LLLT), group 2: high-intensity laser therapy(HILT), group 3: infrared radiation (IR), group 4: placebo was applied. The electrodiagnostic examination was performed on the first day, before a workout and irradiation, as well as 48 hours after the workout. Moreover, pain intensity assessment (VAS) was performed 24 and 48 hours after workouts. A statistically significant increase in the average threshold limit value of accommodation after a workout was observed in the IR group, in contrast to the HILT group, in which a decrease in the average threshold limit value of accommodation was observed. In the IR and LLLT groups, the value of rheobase increased. A statistically significant decrease in pain was observed in the LLLT and IR groups. The post-exercise irradiation with LLLT and incoherent IR influenced a decrease in sensorimotor excitability and decrease in pain of the muscle after a workout.
\end{abstract}

\section{Key words}

low level laser therapy (LLLT), high intensity laser therapy (HILT), infrared radiation (IR), pain, neuromuscular excitability, delayed-onset muscle soreness

\section{INTRODUCTION}

Delayed onset muscle soreness (DOMS) can also be defined as exercise-induced muscle damage (EIMD). It affects people with a low level of fitness who start an intense workout, it can also occur in athletes after excessive exercise $[1,2]$. There may be various symptoms associated with DOMS; ranging from slight tenderness of muscles to intense muscular pain, which significantly impedes daily functioning. Pain and stiffness occur $8-24$ hours after exercise, and peak from $24-48$ hours after exercise [3]. According to Halski, changes in the muscle excitability can be a symptom of muscle fatigue [4].

Various physical factors are useful in eliminating the above symptoms. Thermotherapy and phototherapy are commonly used to relax muscles, reduce myoneural conduction and obtain analgesic effects [5]. Heat was one of the first factors used for the therapeutic purposes [6]. It causes immediate pain relief and improves blood circulation; thus, it accelerates the healing process of the damaged tissue $[7,8]$. Calcium channels, among others, are involved in the reconstructive processes [9]. The channels respond to the heat by increasing the amount of intracellular calcium, which results in the stimulation of the sensory nerves and the feeling of warmth [10]. In a short time, nitric oxide is produced in endothelial cells and is responsible for maintaining the heat circulation. This increase in circulation is considered to be an indispensable factor for tissue protection against heat and repair of the damaged tissues [11]. The heat influence on the nitric oxide metabolism provides an analgesic effect [12].

Specific properties of laser irradiation allow the obtaining of relevant biophysical effects in the tissue, which are reflected

Address for correspondence: Aneta Weres, Department Institute of Physiotherapy, Medical University of Rzeszow, Warszawska 26A, 35-205 Rzeszów, Poland

E-mail: budzinska2@tlen.pl

Received: 18 October 2015; accepted: 20 April 2016 in different levels of the organism functions [13]. Numerous clinical studies have confirmed the usefulness of laser therapy in reducing the symptoms of muscle fatigue [14].

Warm compresses were very useful in the prevention and treatment of an early phase of DOMS [7]. However, Hausswirth et al. showed in their study that systemic cryotherapy applied after a workout was more effective than infrared ray heat therapy (FIR) [15]. According to the studies carried out by Higashi, there were no significant differences between the low-level laser irradiation group (808 $\mathrm{nm}$ wavelength, $100 \mathrm{~mW}$, power density $35.7 \mathrm{~W} / \mathrm{cm}^{2}$, $70 \mathrm{sec} /$ point 7J/point) and the control group, both in the number of muscle cramps and the lactate concentration [16].

\section{OBJECTIVE}

To assess the influence of laser irradiation and incoherent infrared radiation on sensorimotor excitability and selected muscle pain after a workout.

\section{MATERIALS AND METHOD}

Permission to conduct the research was obtained from the Bioethics Commission (Resolution of 13 December 2012). The research was carried out on 40 healthy volunteers (29 women, 11 men), aged 20-21, who have given their written consent to participate in the studyh.

The criteria for exclusion were the following: complaints from the cardiorespiratory system, taking photosensitizing agents, the presence of pigmented lesions in the irradiated area, disorders in the sensory system, past injuries in the lower extremities, and participation in strenuous workouts. The participants of the study were randomly divided into four 
groups. The triceps calf muscle workout was carried out in all the groups (muscle cramps caused by calf raising in 4 workout series, 30 repetitions). Immediately after training, a single phototherapy treatment was applied to all the participants. A post-workout low-level laser therapy (LLLT) was applied in the first group, high-intensity laser therapy (HILT) in the second group, and incoherent infrared radiation (IR) in the third group. A post-workout placebo irradiation was applied in the fourth group.

Low-level laser radiation was emitted by the semiconductor laser CTL $1106 \mathrm{M}(810 \mathrm{~nm})$ with the maximum power of 500 $\mathrm{mW}$. Power of the radiations, performed continuously, was $250 \mathrm{~mW}$, power density $-0.15 \mathrm{~mW} / \mathrm{cm}^{2}$ (for the irradiated area of $1,600 \mathrm{~cm}^{2}$ ). The applied energy density was $0.2 \mathrm{~J} / \mathrm{cm}^{2}$, and total energy of the treatment, depending on the size of the irradiated area, reached a maximum of $300 \mathrm{~J}$.

In high-energy irradiations, laser irradiation was applied, emitted by a HIRO 1.0 laser, with an active medium (semiconductor) Nd:YAG (1064 nm), peak power of a single pulse $1 \mathrm{~kW}$ and the pulse duration in the range of 120 150 microseconds. The irradiations were performed with an average power of $6 \mathrm{~W}$, with applied energy density of $2 \mathrm{~J} / \mathrm{cm}^{2}$ (for the irradiated area of about $1,600 \mathrm{~cm}^{2}$ ), and the total energy of the treatment, depending on the size of the irradiated area, reached a maximum of $300 \mathrm{~J}$.

The basis for the calculation of the applied energy density was the size of the irradiated area, calculated individually for each examined person, taking into account the absolute length of the lower leg (calf) and its circumference. The preliminary approximate measurements indicated that the size of the irradiated area in this age group was in the range of $1,500-1,600 \mathrm{~cm}^{2}$. Iirradiations in the first group and the second group were performed using the contact sweeping method in accordance with the laser methodology.

In the third group, the irradiations were performed with a Sollux lamp with a red filter which emitted incoherent shortwave infrared radiation (with wavelengths from 770-1,400 nanometers), as well as visible red radiation.

Muscle examination included the neuromuscular excitability assessment with an application of the traditional electrodiagnostic method. The examination was performed twice: before a workout and irradiation, as well as 48 hours after the workout. Non-exertional and exertional pain intensity assessment by the Visual Analog Scale (VAS) was performed 24 and 48 hours after workouts.

The results were analysed by the ANOVA (analysis of variance test) and the Kruskal-Wallis test in order to assess significant differences among the examined groups. The t-test for dependent samples and the Wilcoxon test were used to assess the significance of changes between the first and second examinations.

\section{RESULTS}

Statistically significant differences in the level of rheobase before a workout were not observed among the compared groups. In the LLLT and IR groups, the results were similar to the statistically significant result (Fig. 1). In the LLLT and IR groups, the rheobase values were higher (Tab. 1).

A Statistically significant change in the threshold limit value of accommodation after a workout was observed only in the IR group ( $p=0.05$ ) (Fig. 2). An increase in the threshold

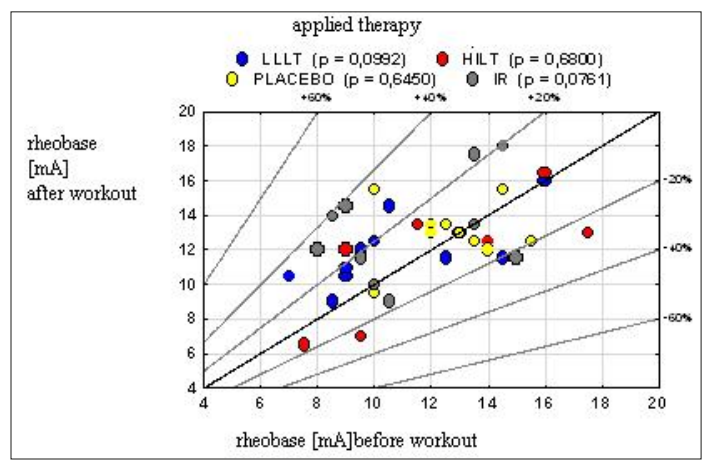

Figure 1. Changes in rheobase values in examined groups

limit value of accommodation in the second examination was observed in this group (Tab. 2).

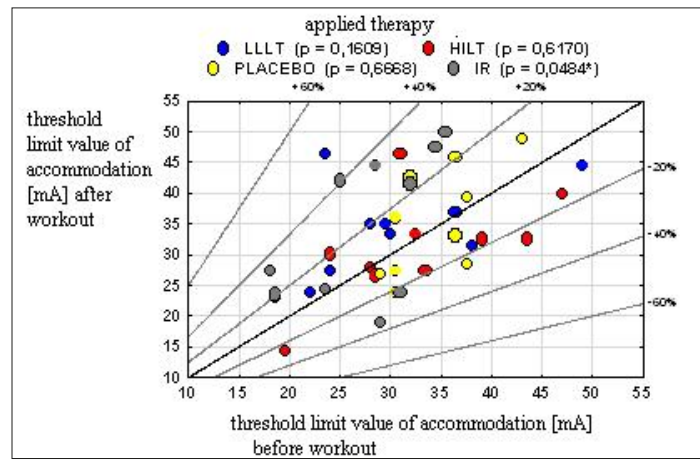

Figure 2. Changes in the threshold limit value of accommodation in examined groups

Table 1. Changes in rheobase values in examined groups

\begin{tabular}{lcccccccccc}
\hline \multirow{2}{*}{$\begin{array}{l}\text { Applied } \\
\text { therapy }\end{array}$} & \multicolumn{10}{c}{ Rheobase [mA] } \\
\cline { 2 - 12 } & \multicolumn{3}{c}{ Before workout } & \multicolumn{3}{c}{ After workout } & \multicolumn{3}{c}{ Change } \\
\cline { 2 - 11 } & $\bar{x}$ & Me & $s$ & $\bar{x}$ & Me & $s$ & $\bar{x}$ & Me & $s$ \\
\hline LLLT & 10.7 & 9.8 & 2.8 & 11.9 & 11.5 & 2.0 & 1.3 & 1.8 & 2.2 \\
\hline HILT & 11.7 & 10.8 & 3.2 & 11.4 & 12.3 & 3.1 & -0.3 & -0.3 & 2.2 \\
\hline PLACEBO & 12.7 & 12.8 & 1.8 & 13.0 & 13.0 & 1.7 & 0.3 & 0.5 & 2.3 \\
\hline IR & 11.2 & 10.3 & 2.6 & 13.2 & 12.8 & 3.0 & 2.0 & 2.8 & 3.1 \\
\hline P ANOVA & & 0.3774 & & & 0.3386 & & & 0.2059 & \\
\hline
\end{tabular}

Table 2. Changes in threshold limit value of accommodation in examined groups

\begin{tabular}{lcccccccccc}
\hline \multirow{2}{*}{$\begin{array}{l}\text { Applied } \\
\text { therapy }\end{array}$} & \multicolumn{9}{c}{ Threshold limit value of accommodation [mA] } \\
\cline { 2 - 12 } & \multicolumn{3}{c}{ Before workout } & \multicolumn{3}{c}{ After workout } & \multicolumn{3}{c}{ Change } \\
\cline { 2 - 11 } & $\bar{x}$ & Me & $s$ & $\bar{x}$ & Me & $s$ & $\bar{x}$ & Me & $s$ \\
\hline LLLT & 29.9 & 28.8 & 9.1 & 33.8 & 34.3 & 7.8 & 3.9 & 3.5 & 8.0 \\
\hline HILT & 32.7 & 31.8 & 8.5 & 31.1 & 31.3 & 8.5 & -1.5 & -3.5 & 7.7 \\
\hline PLACEBO & 34.3 & 34.3 & 4.5 & 35.3 & 34.5 & 8.7 & 0.9 & 0.0 & 6.8 \\
\hline IR & 27.6 & 28.8 & 6.2 & 34.4 & 34.5 & 11.7 & 6.8 & 9.5 & 9.5 \\
\hline $\mathrm{P}_{\text {ANOVA }}$ & & 0.1877 & & & 0.7762 & & & 0.1283 & \\
\hline
\end{tabular}

In order to assess differences concerning the intensity of pain on rest among the examined groups, the non-parametric Kruskal-Wallis test was used. Analysis of the significance of changes in the level of pain between the first and second examination was performed using the non-parametric Wilcoxon test. The changes between the examinations were 
statistically significantly different $(p<0.05)$. In the LLLT and IR groups, the average pain intensity was reduced, although statistically significant changes were observed in the LLLT group. A significant increase in the pain level was observed in the placebo group. The p-value of the test probability was lower than 0.10; thus, it may be presumed that with the larger size of the group, a significant change in the pain level might be observed, although an adverse one (Tab. 3).

Table 3. Changes in non-exertional pain level in examined groups

\begin{tabular}{lcccccccccc}
\hline \multirow{2}{*}{$\begin{array}{l}\text { Applied } \\
\text { therapy }\end{array}$} & \multicolumn{8}{c}{ Non-exertional pain intensity } \\
\cline { 2 - 12 } & \multicolumn{3}{c}{ Before workout } & \multicolumn{3}{c}{ Post-workout } & \multicolumn{3}{c}{ Change } \\
\cline { 2 - 12 } & $\bar{x}$ & Me & $s$ & $\bar{x}$ & Me & $s$ & $\bar{x}$ & Me & $s$ \\
\hline LLLT & 1.4 & 1.0 & 1.8 & 0.9 & 0.0 & 1.7 & -0.5 & -0.5 & 0.5 \\
\hline HILT & 0.3 & 0.0 & 0.5 & 0.7 & 0.0 & 1.2 & 0.4 & 0.0 & 1.1 \\
\hline PLACEBO & 0.5 & 0.0 & 1.3 & 1.5 & 0.5 & 2.5 & 1.0 & 0.5 & 1.8 \\
\hline IR & 1.3 & 0.0 & 2.1 & 1.1 & 0.0 & 2.3 & -0.2 & 0.0 & 0.8 \\
\hline$P_{\text {Kruskala-Wallisa }}$ & & 0.1496 & & & 0.7083 & & & $\mathbf{0 . 0 1 9 1 *}$ \\
\hline
\end{tabular}

The results of exertional pain intensity were similar to the results for the non-exertional pain $(\mathrm{p}<0.01)$ (Fig. 3). Results of the Wilcoxon test indicated a statistically significant increase in the level of pain in the HILT and PLACEBO groups (Fig. 3). Two other groups showed a reduction in the level of pain, although it was not statistically significant (Tab. 4).

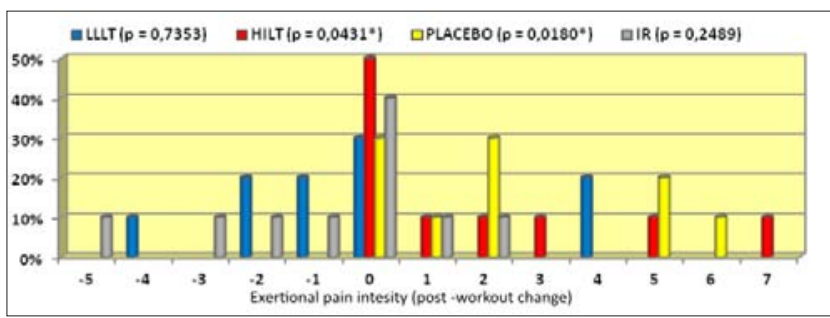

Figure 3. Change in exertional pain level in examined groups

Table 4. Changes in values of exertional pain before workout and after workout. Average values of pain level in I and II examinations

\begin{tabular}{|c|c|c|c|c|c|c|c|c|c|}
\hline \multirow{3}{*}{$\begin{array}{l}\text { Applied } \\
\text { therapy }\end{array}$} & \multicolumn{9}{|c|}{ Exertional pain intensity } \\
\hline & \multicolumn{3}{|c|}{$\begin{array}{c}24 \text { hours after } \\
\text { Workuto }\end{array}$} & \multicolumn{3}{|c|}{$\begin{array}{c}48 \text { hours after } \\
\text { workout }\end{array}$} & \multicolumn{3}{|c|}{ Change } \\
\hline & $\bar{x}$ & $\mathrm{Me}$ & $s$ & $\bar{x}$ & $\mathrm{Me}$ & $s$ & $\bar{x}$ & Me & $s$ \\
\hline LLLT & 3.1 & 3.0 & 2.7 & 2.9 & 2.0 & 3.1 & -0.2 & -0.5 & 2.5 \\
\hline HILT & 2.3 & 2.5 & 2.0 & 4.1 & 3.0 & 3.6 & 1.8 & 0.5 & 2.5 \\
\hline PLACEBO & 2.2 & 2.0 & 2.2 & 4.5 & 5.0 & 3.5 & 2.3 & 2.0 & 2.3 \\
\hline IR & 2.3 & 2.0 & 2.3 & 1.5 & 1.0 & 2.0 & -0.8 & 0.0 & 2.0 \\
\hline$P_{\text {Kruskala-Wallisa }}$ & \multicolumn{3}{|c|}{0.8730} & \multicolumn{3}{|c|}{0.1608} & \multicolumn{3}{|c|}{$0.0085^{* *}$} \\
\hline
\end{tabular}

\section{DISCUSSION}

The study performed focused on the influence of selected methods of phototherapy on the sensorimotor excitability and level of muscle's pain after workout. Changes in the excitability occured in the course of the DOMS syndrome. Many studies on the mechanisms, therapeutic activities, and preventive strategies concerning the delayed onset muscle soreness after exercise have been published in contemporary literature. The studies show differences in the measurement tools used and methods of assessment of the existing symptoms $[16,17,18]$. Various therapeutic factors have been used so far in experiments on the reduction of the symptoms of DOMS.

The effectiveness of dry heat and moist heat was compared in the studies on the DOMS syndrome. The most effective in the reduction of pain was the treatment which used warm, wet compresses [19]. Another study showed that cold, as well as hot and cold contrast hydrotherapeutic treatment, were effective in regaining isometric and dynamic strength as well as in reducing a local oedema of the tired muscle [20].

Leal et al. showed that LED irradiations $(660 / 850 \mathrm{~nm}$, $10 / 30 \mathrm{~mW}, 30 \mathrm{sec} /$ point, 10 points, total energy $41.7 \mathrm{~J}$ ) 5 minutes after exercise were more effective in the process of muscle regeneration than an immersion in cold water. A statistically significant change in the lactate concentration and creatine kinase could only be observed after irradiations [21].

Impulse conduction velocity in the nerve fibres is dependent on the nerve temperature. The studies carried out by Chatfield et al. [22] and Collins et al. [23] reveal that nerve conduction velocity is reduced by an average of $2 \mathrm{~m} / \mathrm{s}$ with decreasing temperature of the nerve with every 1 degree of Celsius. According to Brederson, however, the heat can reduce pain by limitation of the nerve conduction [24]. In an experimental group, in which LED irradiations of the biceps muscle were applied (LED having a wavelength of $880 \mathrm{~nm}$ and visible LEDs $660 \mathrm{~nm}, 8 \mathrm{~J} / \mathrm{cm}^{2}$ ), the pain connected with DOMS was much smaller than in the control group or the placebo therapy group [25]. Kakihata et al. attempted to investigate the effects of low intensity laser $(660 \mathrm{~nm})$, on the surae triceps muscle fatigue and power during vertical jump in sedentary individuals. Volunteers were divided into three groups: 1) without performing low intensity laser (control); 2) 6 days of low intensity laser applications; and 3) 10 days of low intensity laser applications. The low intensity laser had no significant effects on the variables evaluated [26].

In contrast, the study by Toma et al. aimed to investigate the effects of LLLT on skeletal muscle fatigue in elderly women. Twenty-four subjects divided into 2 groups entered a crossover randomized triple-blinded placebo-controlled trial. Active LLLT (808 nm wavelength, $100 \mathrm{~mW}$, energy $7 \mathrm{~J}$ ) or an identical placebo LLLT was delivered on the rectus femoris muscle immediately before a fatigue protocol. A significant difference was observed in the number of repetitions between groups after active LLLT, subjects demonstrated significantly higher number of repetitions [27].

Studies carried out by Felismino et al. showed that after low-level laser irradiation $(808 \mathrm{~nm} ; 100 \mathrm{~mW} ; 1 \mathrm{~J} /$ irradiated point for $10 \mathrm{~s}$ at 4 points of the biceps muscle of each limb) 72 hours after the muscle workout the creatine kinase activity was weakened, compared with the control group. The irradiations did not have a positive impact on the return of muscle strength [17]. Leal-Junior et al. performed a systematic review with meta-analysis to investigate the effects of phototherapy applied before, during and after exercises. The most significant and consistent results were found with red or infrared wavelengths and phototherapy application before exercises, power outputs between $50-200 \mathrm{~mW}$ and doses of 5 and 6 J per point (spot). The authors concluded that phototherapy (with lasers and LEDs) improves muscular performance and accelerates recovery, mainly when applied before exercise [28]. The aim of study by Antonialli et al. was 
to evaluate the effects of phototherapy with the combination of different light sources on skeletal muscle performance and post-exercise recovery, and to establish the optimal energy dose. Pre-exercise phototherapy with the combination of lowlevel laser and LEDs, mainly with a $30 \mathrm{~J}$ dose, significantly increased performance, decreases DOMS, and improves biochemical marker related to skeletal muscle damage [29]. Weres et al. in their research showed that a dose $0.2 \mathrm{~J} / \mathrm{cm}^{2}$ was more effective than the placebo effect. A single phototherapy treatment as a factor stimulating metabolic processes in the tissue, and at the same time reducing the symptoms of fatigue, was applied in the research carried out by the author of this publication. The post-workout decrease in the rheobase value was observed only in the high-intensity laser therapy group (HILT). In the other groups, the value was increased [30]. According to Pisula et al., the rheobase value increase can be viewed in terms of an increase in stabilization of the polarization in the nerve, and thus greater resistance to external and internal factors [31]. An increase in the threshold limit value of accommodation can also be viewed in the aspect of the resistance improvement to exogenous and endogenous factors. The studies by the author of the presented research show an increase in the threshold limit value of accommodation in all groups, with the exception of the HILT group. The largest increase in this value was observed in the IR group. The observed changes could indicate that phototherapy which uses LLLT and IR causes a decrease in the neuromuscular excitability, and thus reduces the sensitivity to painful stimuli. Also, according to Eukowicz et al., an increase in the sensory excitability threshold after laser irradiation can be interpreted as the analgesic effect of this therapy [14]. Such inference was confirmed in the results of research concerning pain intensity carried out by the author of the current study. Changes in the intensity of pain point to the accelerated rate of the tissue regeneration after low-level laser irradiation. A statistically significant decrease pain in rest level was observed in the LLLT group between the first and second examination. In the other groups, the level of pain did not change, although on the basis of the result obtained for the PLACEBO group, it may be presumed that with the larger size of the group a significant change in the pain level might be observed, although an adverse one. The results of the exertional pain are similar to the results obtained for the pain on rest, although they were more pronounced. Differences among the examined groups in the range of obtained irradiation effects were statistically highly significant. There was quite a significant increase in the level of pain in the HILT and PLACEBO groups in the second examination $(\mathrm{p}<0.05)$, while the other groups showed a reduction in the level of pain, but this was not significant.

The conducted research project points to the usefulness in reducing the DOMS symptoms by the methods of phototherapy which do not provide deep heating to the muscle tissue. Low-level laser therapy (LLLT) and infrared radiation (IR), which are characterised by a much smaller penetration depth, are more useful than the HILT radiation. Slower post-workout resolution of pain in the HILT group may have been caused by the thermal effect which is connected with this therapy (Zalewski et al., 2008). This effect occurs when medium and high power density is used, and thus constitutes a limitation to the use of the high intensity laser therapy (HILT) for recent injuries and acute inflammations $[14,32]$.
Further clinical research into the use of thermal and non-thermal methods of phototherapy which boost the regression of symptoms of the delayed onset muscle soreness is indispensable, so that the methods of phototherapy could be recognised as adjunctive factors with indisputable effectiveness in the muscle workout.

\section{CONCLUSIONS}

1. Post-exercise irradiation of the triceps calf muscle with a low-level laser therapy (LLLT) and incoherent infrared radiation influence a decrease in sensorimotor excitability of the muscle after a workout.

2. Low-level laser therapy and polychromatic/incoherent infrared radiation accelerate the post-workout resolution of pain.

3. The effectiveness of the high-intensity laser therapy HILT in eliminating the symptoms of delayed onset muscle soreness was not confirmed.

\section{REFERENCES}

1. Cheung K, Hume PA, Maxwell L. Delayed onset muscle soreness: Treatment strategies and performance factors. Sports Med. 2003; 33: 145-164.

2. Paulsen G, Crameri R, Benestad HB, Fjeld JG, Mørkrid L, Hallén J, Raastad T. Time course of leukocyte accumulation in human muscle after eccentric exercise. Med Sci Sports Exerc. 2010; 42: 75-85.

3. Prasartwuth O, Taylor JL, Gandevia SC. Maximal force, voluntary activation and muscle soreness after eccentric damage to human elbow flexor muscles. J Physiol. 2005; 15: 337-348.

4. Halski T, Konieczny G, Rusinowska A, Rieger L, Psalmister E. Electrical neuromuscular excitability after doing exercise. Fizjoterapia 1999; 7: 24-27.

5. Szpotowicz B, Polak A, Gieremek K, Kucio C, Kubacki J, Czech P. Study of the effects of cryotherapy and diathermy on cutaneous nerve excitability in healthy people. Fizjoter Pol. 2011; 11: 123-134.

6. Fleetwood-Walker SM, Proudfoot CW, Garry EM, Allchorne A, VinuelaFernandez I, Mitchell R. Cold comfort pharm. Trends Pharmacol Sci. 2007; 28: 621-628.

7. Mayer JM, Mooney V, Matheson LN, Erasala GN, Verna JL, Udermann $\mathrm{BE}$, Leggett $\mathrm{S}$. Continuous low-level heat wrap therapy for the prevention and early phase treatment of delayed-onset muscle soreness of the low back: a randomized controlled trial. Arch Phys Med Rehabil. 2006; 87: $1310-1317$.

8. Petrofsky JS, Laymon M. Heat transfer to deep tissue: the effect of body fat and heating modality. J Med Eng Technol. 2009; 33: 337-348.

9. Perálvarez-Marín A, Doñate-Macian P, Gaudet R. What do we know about the transient receptor potential vanilloid 2 (TRPV2) ion channel? FEBS J. 2013; 280: 5471-87.

10. Chao CC, Hsieh SC, Tseng MT, Chang YC, Hsieh ST. Patterns of contact heat evoked potentials (CHEP) in neuropathy with skin denervation: correlation of CHEP amplitude with intraepidermal nerve fiber density. Clin Neurophysiol. 2008; 119: 653-661.

11. Petrofsky J, Berk L, Bains G, Khowailed IA, Hui T, Granado M, Laymon M, Lee H. Moist heat or dry heat for delayed onset muscle soreness. J Clin Med Res. 2013; 5: 416-425.

12.Skalska-Izdebska.R, Zwolińska J, Weres A, Zając L. The possibilities of using a variable magnetic field in the treatment of diseases and injuries of the musculoskeletal. Zamojskie Studia i Materiały 2006; 8: 167-173

13. Kwolek A, Zwolińska J, Weres A. The influence of the therapeutic dose on the effectiveness of laser therapy low - and high-energy (HILT). Acta Bio-Opt Inform Med. 2011; 17: 171-178.

14. Łukowicz M, Pawlak A, Pawlikowski J, Weber-Zimmermann M, Zalewski P. High-energy laser therapy (HILT) - clinical applications. Acta Bio-Opt Inform Med. 2007; 13: 326-330.

15. Hausswirth C, Louis J, Bieuzen F, Pournot H, Fournier J, Filliard JR, Brisswalter J. Effects of whole-body cryotherapy vs. far-infrared vs. passive modalities on recovery from exercise-induced muscle damage 
in highly-trained runners. PLOS One, 2011; 6(12): e27749. doi:10.1371/ journal. Pone.0027749.

16. Higashi RH, Toma RL, Tucci HT, Pedroni CR, Ferreira PD, Baldini G, Aveiro MC, Borghi-Silva A, de Oliveira AS, Renno AC. Effects of lowlevel laser therapy on biceps braquialis muscle fatigue in young women. J Photomed Laser Surg. 2013; 31: 586-594

17. Felismino AS, Costa EC, Aoki MS, Ferraresi C, de Araújo Moura Lemos TM, de Brito Vieira WH. Effect of low-level laser therapy $(808 \mathrm{~nm})$ on markers of muscle damage: a randomized double-blind placebocontrolled trial. Lasers Med Sci. 2014; 29: 933-938.

18. Al-Nakhli HH, Petrofsky JS, Laymon MS, Berk LS. The use of thermal infra-red imaging to detect delayed onset muscle soreness. J Vis Exp. 2012; 22: 3551.

19. Petrofsky J, Batt J, Bollinger JN, Jensen MC, Maru EH, Al-Nakhli HH. Comparison of different heat modalities for treating delayed-onset muscle soreness in people with diabetes. Diabetes Technol Ther. 2011; 13: 645-655.

20. Vaile J, Halson S, Gill N, Dawson B. Effect of hydrotherapy on the signs and symptoms of delayed onset muscle soreness. Eur J App Physiol. 2008; 102(4): 447-55.

21.Leal Junior EC, de Godoi V, Mancalossi JL, Rossi RP, De Marchi T, Parente M, Grosselli D, Generosi RA, Basso M, Frigo L, Tomazoni SS, Bjordal JM, Lopes-Martins RA. Comparison between cold water immersion therapy (CWIT) and light emitting diode therapy (LEDT) in short-term skeletal muscle recovery after high-intensity exercise in athletes--preliminary results. Laser Med Sci. 2011; 26: 493-501.

22. Chatfield PO, Battista AF. Effects of cooling on nerve conduction in a hibernator and non-hibernator. Am J Physiol. 1948; 155: 179-185.

23. Collins K, Storey M, Peterson K. Peroneal nerve palsy after cryotherapy. Physician Sports Med. 1986; 14: 105-108

24. Brederson JD, Kym PR, Szallasi A. Targeting TRP channels for pain relief. Eur J Pharmacol. 2013; 716: 61-76.
25. Douris P, Southard V, Ferrigi R, Grauer J, Katz D, Nascimento C, Podbielski P. Effect of phototherapy on delayed onset muscle soreness. J Photomed Laser Surg. 2006; 24: 77-82.

26. Kakihata CM, Malanotte JA, Higa JY, Errero TK, Balbo SL, Bertolini GR. Influence of low-level laser therapy on vertical jump in sedentary individuals; Einstein (Sao Paulo), 2015; 13(1): 41-6.

27. Toma RL, Tucci HT, Antunes HK, Pedroni CR, de Oliveira AS, Buck I, Ferreira PD, Vassão PG, Renno AC. Effect of $808 \mathrm{~nm}$ low-level laser therapy in exercise-induced skeletal muscle fatigue in elderly women. Lasers Med Sci. 2013; 28(5): 1375-82.

28. Leal-Junior EC, Vanin AA, Miranda EF, de Carvalho Pde T, Dal Corso S, Bjordal JM. Effect of phototherapy (low-level laser therapy and light-emitting diode therapy) on exercise performance and markers of exercise recovery: a systematic review with meta-analysis. Lasers Med Sci. 2015; 30(2): 925-39.

29. Antonialli FC, De Marchi T, Tomazoni SS, Vanin AA, dos Santos Grandinetti V, de Paiva PR, Pinto HD, Miranda EF, de Tarso Camillo de Carvalho P, Leal-Junior EC. Phototherapy in skeletal muscle performance and recovery after exercise: effect of combination of super-pulsed laser and light-emitting diodes. Lasers Med Sci. 2014; 29(6): 1967-76.

30. Weres A, Zwolińska J, Kwolek A. Effect of low a level laser therapy (LLLT) - and a high intensity laser radiation (HILT) on the sensory and motor excitability of a healthy muscle after workout [in:] Pop T. (editor), The value of rehabilitation in the consciousness of contemporary man. Wydawnictwo Uniwersytetu Rzeszowskiego, 2014: 283-294.

31. Pisula A, Jackowski E, Łazowski J. The effect of a single magnetic stimulation on the electrical excitability of the muscles. Acta Bio-Opt Inform Med. 2004; 10: 119-122.

32.Zalewski P, Łukowicz M, Zając A, Szymańska J, Ciechanowska K. Infrared analysis of the thermal effects of high-energy laser HILT depending on the dose energy irradiation, wavelength and application techniques, Biomedical Engineering. Acta Bio-Opt Inform Med. 2008; 14: 21-24. 